\title{
Gestão democrática do patrimônio cultural em São Francisco do Sul (SC)
}

Vanessa Maria Pereira*

\section{Resumo}

Pensar a gestão democrática do patrimônio cultural de um lugar, seja qual for sua natureza, suscita um série de discussões, principalmente no que diz respeito a sua legitimidade social, isto por estarem dia-a-dia dialogando com problemas socioeconômicos, pressões imobiliárias e uma série de outros fatores.

O presente artigo fará menção ao caso de São Francisco do Sul, Santa Catarina, o existente projeto de caráter econômico e social, pautado na preservação do patrimônio histórico, bem como as ações realizadas por instituições governamentais e não governamentais no sentido de democratizar o acesso a este patrimônio com ênfase ao trabalho realizado pelo Museu Nacional do Mar.

Palavras-chave: Gestão democrática do patrimônio. São Francisco do Sul. Museu Nacional do Mar.

\section{Cultural heritage democratic management in São Francisco do Sul (SANTA CATARINA)}

\begin{abstract}
To think about cultural heritage democratic management of a place, whatever its nature is, brings about a series of discussions, mainly in what concernes its social legitimacy, as being day after day dialoguing with social and economical issues, land pressures and many other factors.
\end{abstract}

The present article will mention the case of São Francisco do Sul, Santa Catarina, the economic and social character existing project, ruled by the cultural heritage preservation, as well as the actions carried through for governmental and non governmental institutions with the purpose of democratizating the access to this heritage with emphasis to the work carried out by the Museu Nacional do Mar. 
Key-words: Cultural heritage democratic management. São Francisco do Sul. Museu Nacional do Mar.

São Francisco do Sul é uma pequena cidade que está localizada no litoral norte catarinense bem próximo a Joinville - maior cidade do Estado de Santa Catarina -, distando apenas $40 \mathrm{~km}$, e entre Florianópolis e Curitiba. A maior parte do município concentra-se em sua parte insular.

Além de possuir belas praias, São Francisco do Sul tem um dos maiores portos do Estado - este se localiza bem próximo ao Centro Histórico -, e a linha perimetral da área tombada é praticamente tangente à área do Porto. Seu principal ramo de atividade é o graneleiro; atualmente trabalha também com containeres.

O Centro Histórico de São Francisco do Sul foi tombado, em 1981, pelo município, e em 1987, pelo IPHAN, com destaque ao seu valor paisagístico. Não existe no município tombamento de monumentos isolados realizados pela esfera federal.

Em São Francisco do Sul, como em qualquer centro urbano, existe uma forte pressão imobiliária sobre valores e possíveis utilizações dos imóveis, com a agravante que em centros tombados a propriedade privada está submetida a uma série de leis de proteção. Vale ressaltar aqui, que embora seja inconcebível pensar os monumentos urbanos dissociados de seu contexto, o tombamento do conjunto agrava os "problemas" imobiliários nessas regiões, isto porque, como coloca De Fusco em seu livro "Arquitectura como Mass midium":

Las zonas en donde están situados tienen en valor comercial elevado; los proprietarios no pueden desprenderse de ellos, y quando lo hacen no puden obtener los beneficios que se obtiene de sitios ocupados por inmuebles comunes; se consideran víctimas del sistema semiliberal. Según lá economía de mercado y la ética liberal, el problema resulta insoluble, y se agrava por el hecho de que no se trata de salvagardar solamente unos edifícios sino todo el ambiente de un centro histórico. En algunos casos, puede obtenerse una renta considerable de 
uno edificio monumental adaptándolo a una funciona publica o de representación, pero los edificios que lo circundan y que surgieron para cumplir funciones subalternas de aquél, no tienen en la actualidad función alguna, no son 'rentables' y se abandonan a su desgaste natural. (1970, p.100-101)

A proximidade com o Porto e a necessidade da instalação de uma série de serviços de apoio a este, atuam diretamente sobre a regulação dos preços dos imóveis, que passam a ser alugados ou vendidos por valores impraticáveis para a moradia, mas bastante razoáveis para instalação de empresas. Como conseqüência deste processo, a proliferação de escritórios de agentes marítimos, despachantes, entre outros, reduz a diversidade de funções, contribuindo para a morte gradual dos usos corriqueiros e das relações interpessoais, principalmente fora dos horários comerciais.

Não se pode negar que para os proprietários dos imóveis estes escritórios representam uma valiosa fonte de renda e, mais uma vez, como destaca De Fusco:

En un país pobre, en el que a propriedad es la única forma sólida de precisión y en el que como consecuencia, los esfuerzos y las esperanzas de los individuos siempre están puestos en la propriedad, es difícil que se pueda "convencer" a alguien de la oportunidad de mantener y como caonsecuencia, de gastar para mantener. (1970, p.101)

Caso não seja oferecida uma nova possibilidade a estes proprietários, a tendência é a utilização monofuncional, voltada à prestação de serviços portuários, no Centro Histórico de São Francisco do Sul.

Como forma de responder ao anseio de oferecer uma alternativa, surge o projeto de investir na cidade, não somente recursos financeiros para recuperação do patrimônio, mas principalmente, um trabalho processual para que a população local desperte para a questão da preservação do patrimônio material e imaterial. O projeto desenvolvido pelo IPHAN e viabilizado pela Prefeitura Municipal e pelo Programa Monumenta do Governo Federal sugere que São Francisco do Sul se torne um "Centro Regional de Lazer". A proposta vem atender uma demanda local e regional, já que grandes cidades 
próximas, como Joinville, Blumenau e até mesmo Curitiba oferecem poucas alternativas de lazer desta natureza.

Trabalhar o turismo, mesmo que regional, em patrimônios urbanos, é sempre uma ação polêmica e que suscita muita discussão. No livro "A alegoria do patrimônio", Françoise Choay coloca o tema exaustivamente. A autora levanta uma questão pertinente quando discorre sobre o papel museal das figuras históricas, ressalta que:

A cidade antiga, como figura museal, ameaçada de desaparecimento, é concebida como um objeto raro, frágil, precioso para a arte e para a história e que, como as obras conservadas nos museus, deve ser colocada fora do circuito da vida. Tornando-se histórica, ele perdeu sua historicidade. (2001, p.191)

E é, justamente, para evitar essa perda de historicidade, gerando assim a museificação, que nos casos de cidades brasileiras, fatalmente levariam ao arruinamento dos bens protegidos, que se pensa um projeto amplo de implantação gradual e territorialmente não concentrada.

Um pouco mais adiante em seu discurso, comentando as posições de Giovannoni, Choay esclarece:

Com a condição de que recebam tratamento conveniente, isto é, desde que neles não se implantem atividades incompatíveis com sua morfologia, essas malhas urbanas antigas ganham dois novos privilégios: elas são, da mesma forma que os monumentos históricos, portadoras de valores artísticos e históricos, bem com de valor pedagógico e de estímulo imaginado por Viollet-le-Duc e por Sitte, verdadeiros catalisadores no processo de invenção de novas configurações espaciais. (2001, p.198)

É importante salientar que, diferentemente da realidade da grande maioria dos centros históricos brasileiros, os antigos moradores do centro de São Francisco do Sul são, em grande parte, pessoas de classe média, pequenos comerciantes e prestadores de serviço, que nunca chegaram a abandonar seus imóveis.

O projeto que vem sendo executado pela Prefeitura e Programa Monumenta, além de oferecer uma nova alternativa de trabalho e renda para a população francisquense 
como um todo, recuperou na cidade algumas tradições e proporcionou novas formas de relacionamento pessoal.

Entre as obras já realizadas ou em andamento, pode-se destacar algumas realizadas em monumentos históricos:

1 - Recuperação física do Museu Nacional do Mar: o maior museu de embarcações brasileiras do país, instalado nos galpões de uma antiga companhia de navegação;

2 - Recuperação da Igreja Matriz Nossa Senhora das Graças;

3 - Reconstrução dos antigos armazéns Santista para a instalação do Terminal (Porto) Turístico de São Francisco do Sul;

4 - Recuperação do Mercado Municipal, que manterá os usos originais.

Outras ações de grande relevância para a abrangência do Projeto são:

1 - Urbanização da Orla Marítima do Centro Histórico: proporcionou que áreas degradadas pelo uso inapropriado de automóveis e a falta de cuidado dos moradores e poder público fosse colocada em condições de uso, iluminada e humanizada, de forma que, após esta recuperação, é comum ver moradores caminhando ou passeando, inclusive no período noturno, hábito bastante recente.

2 - Recuperação do Clube XXIV de Janeiro: a reestruturação física do Clube foi pensada de forma que este, que é o mais tradicional Clube Social da cidade, tenha condições financeiras de se manter e volte a realizar as atividades cotidianas que há alguns anos estavam canceladas.

3 - Recuperação de imóveis privados: esta talvez seja a mais importante das ações do Programa. Através de uma parceria com a Caixa Econômica Federal, foi oferecido aos moradores locais um financiamento com condições bastante facilitadas para recuperação de seus imóveis; isto contribui para que o conjunto urbano como um todo seja mantido. 
Embora a previsão de término do Programa Monumenta seja final de 2006, a Prefeitura Municipal ainda solicitou a este uma série de ações, tais como: implantação da nova biblioteca municipal, recuperação do Museu Histórico, implantação do Museu de Arte Sacra, criação de um parque municipal, ampliação do projeto de urbanização para outras áreas que não a da orla, ampliação do programa de financiamento de recuperação de imóveis privados para incorporar todas as edificações existentes no centro tombado (e não somente da área de abrangência do Programa, um pouco menor), entre outras.

Dessa forma acredita-se que o projeto de futuro idealizado para São Francisco do Sul evita o processo de museificação e de banalização do Centro Histórico e contribui para a diversidade de usos e a permanência dos moradores locais. O que se tentou, e ainda se tenta, é não permitir que

A "embalagem" que se dá ao patrimônio histórico urbano tendo em vista seu consumo cultural, assim como o fato de ser alvo de investimentos do mercado imobiliário de prestígio, tende a excluir deles as populações locais ou não privilegiadas e, com elas, suas atividades tradicionais e modestamente cotidianas. (CHOAY, 2001).

Para tanto, algumas entidades começam a realizar atividades em prol da manutenção das tradições, da difusão cultural e da perpetuação dos valores do patrimônio francisquense.

No sentido de exemplificar algumas destas ações serão descritas as atividades realizadas pelo Museu Nacional do Mar, o maior e mais completo museu sobre embarcações brasileiras do país.

Os projetos realizados em $2005 / 2006$, alguns encerrados, outros ainda em andamento, têm a intenção de democratizar o acesso, não apenar físico, mas também social, à cultura. Entre eles podemos destacar:

1 - Aquisição e instalação de elevadores e plataforma elevatória: o projeto realizado com o apoio financeiro da Fundação Vitae é uma tentativa do Museu de permitir que qualquer pessoa, necessitando ou não de acessos facilitados, possa fazer o trajeto oficial de visitação, sem prejuízos à compreensão 
dinâmica museal; além disso, é um primeiro passo de uma série de ações que pretende difundir no município a preocupação com a acessibilidade universal.

2 - Primeiro Seminário do Patrimônio Naval Brasileiro: realizado com o apoio do Programa Monumenta, em março de 2005, foi idealizado com a finalidade de discutir o atual cenário do patrimônio naval nacional. Houve uma participação bastante abrangente de representantes dos Estados da Federação, entre técnicos da cultura, turismo e meio ambiente, modelistas, navegadores, e sociedade civil em geral. Um dos resultados mais expressivos é a publicação dos Anais do Seminário, um importante documento para o registro da atual situação deste rico patrimônio nacional.

3 - Treinamento de pescadores artesanais: também com o apoio do Programa Monumenta, a idéia do projeto é treinar pescadores para fazerem passeios turísticos pela Baía da Babitonga. Não tem a intenção de tirá-los da atividade pesqueira, mas permitir que em períodos nos quais a pesca não for permitida, tenham um trabalho garantido que Ihes possa oferecer uma renda extra, garantindo, assim, a manutenção das embarcações em uso e conseqüente preservação das mesmas. É importante destacar que estes passeios serão gerenciados pelo próprio Museu, em parceria com os pescadores. Assim os visitantes ou qualquer interessado em realizar os passeios terá a possibilidade de conhecer a cidade guiados por um pescador local que expressará sua forma de ver e apreender a cidade, viabilizando uma rica troca cultural.

4 - Projetos de qualificação do acervo, que entre outras coisas priorizam ações voltadas para a educação. Entre eles podemos destacar: "gaveteiros do saber", com patrocínio da Petrobrás; consistirá num material de apoio didático focado nas áreas de história e biologia para ser usado pelos professores em aulas variadas. Pretende-se que este material esteja disponível também na biblioteca do Museu para que os professores possam montar as aulas preparatórias. Outro projeto que abrange a criação de material didático é a elaboração dos painéis rotulados, com patrocínio da Caixa Econômica Federal; estes estão focados nas áreas mais relacionadas à geografia. Com este material, além das crianças aprenderem sobre barcos, também terão a oportunidade de saber um 
pouco mais sobre as regiões brasileiras, populações, conceitos básicos de geografia, etc. Além de textos e imagens, os painéis contarão com maquetes ilustrativas, referentes aos temas abordados.

5 - Qualificação da Loja de Artesanato: contemplado pelo Programa "Cultura Viva", do Ministério da Cultura, prevê a aquisição de artesanato de todo Brasil para que a loja se torne um ponto de difusão deste trabalho, além de possuir o cadastro dos artesãos que tenham seus produtos expostos a fim de divulgar os trabalhos de qualidade realizados pelo país.

6 - Sarau literário: evento realizado pelo Museu, sem apoio financeiro externo, atrai crianças e adultos que apresentam suas crônicas, contos, poesias e toda expressão da arte em geral. O público jovem é bastante presente. Em 2006 o evento passou a chamar-se "Sarau Artístico" em razão da multiplicidade de apresentações que foram surgindo espontaneamente.

7 - Semana de Santa Catarina: é um projeto cultural e artístico que tenta trazer o público em geral, principalmente crianças e moradores, como forma de incentivá-los a apropriarem-se do espaço do Museu. É na verdade, por meio de outras atividades, oficinas, palestras e apresentações artísticas, que as pessoas são atraídas inicialmente ao Museu, familiarizando-se com o ambiente, para que se tornem público assíduo, não só do Museu Nacional do Mar, mas em instituições culturais em geral. No ano de 2005 o evento foi patrocinado, através da Lei de Incentivo à Cultura da FCC (Fundação Catarinense de Cultura), pela Cia. Fabril Lepper, além de contar com apoio do Terminal Santa Catarina, Univille (Universidade da Região de Joinville), e mais uma série de empresários locais.

8 - Implantação da Escola de Remo: é um trabalho que faz parte do projeto da Escola de Navegação do Museu é voltado para alunos da rede municipal de ensino. A Escola ainda não foi implantada, mas foi aprovado pela FCC na Lei de Incentivo à Cultura o projeto para aquisição das embarcações, e uma série de ações infra-estruturais estão sendo realizadas com apoio do IPHAN para instalação da mesma. 
9 - Liceu de Artes e Ofícios: recentemente aprovado pelo Programa Monumenta, este curso será voltado à formação de jovens de todo o país em modelismo e artesanato naval, com ênfase dada aos jovens francisquenses. $O$ projeto prevê um curso de três meses, oferecido a duas turmas, cada uma delas com dez jovens, que freqüentarão aulas teóricas sobre cultura, patrimônio brasileiro (cultural, arquitetônico, naval, etc), além de aulas práticas sobre modelismo e artesanato naval. Dessa forma pretende-se impulsionar à produção de artesanato de qualidade em todo país. Um centro de formação para que eles voltem às suas cidades, e disseminem seu conhecimento, entrando no circuito comercial, que além de proporcionar trabalho digno para estes jovens, colocará no mercado artesanato de qualidade, que faça jus ao nosso rico e variado patrimônio naval.

Com todas estas ações em curso, o Museu Nacional do Mar pretende, primeiramente promover a salvaguarda do patrimônio naval brasileiro, participando ativamente e promovendo encontros e discussões sobre o mesmo, diagnósticos e formas de preservação, promovendo atividades que valorizem e estimulem pescadores, modelistas, artesãos e navegadores, de forma que estas atividades ligadas ao mar permaneçam sendo realizadas de forma autêntica, por quem realmente as dominam. Dentre as demais missões do Museu pode-se destacar: disponibilização do acervo ao maior número de visitantes possível, promovendo acessibilidade física e social, buscando estimular a participação de moradores da região; fazer da biblioteca uma referência nacional no tema, que possa atender desde estudantes curiosos aos mais gabaritados especialistas; fazer do espaço físico do Museu um lugar pedagógico complementar, no qual os professores encontram material específico, além de uma série de possibilidades sinestésicas, maquetes, réplicas de animais, músicas, etc. Assim, mais do que um espaço de observação, o Museu se torna um espaço de experimentação, onde o aprendizado se dá de forma fluída.

Colocar, aqui, o exemplo do Museu é fundamental, pois este é um ponto de difusão cultural, no qual queremos que a cidade se espelhe; todo esse trabalho é feito com o 
objetivo de aproximar a comunidade e fazer com que ela tenha orgulho de "ter" este Museu, e com isso ter orgulho da própria cidade. A existência do Museu Nacional do Mar enquanto monumento arquitetônico na paisagem associada à apropriação de seus espaços e atividades culturais faz com que os francisquenses se reconheçam e valorizem sua identidade, principalmente sua individualidade e autenticidade frente às demais cidades.

\section{Referências bibliográficas}

CHOAY, Francoise. A alegoria do patrimônio. São Paulo: Estação Liberdade; Unesp, 2001.

DE FUSCO, Renato. Arquitectura como mass medium: notas para una semiologia arquitectonica. Barcelona: Anagrama, 1970.

* Arquiteta e Urbanista graduada pela Universidade Federal de Santa Catarina (UFSC). Mestranda em "Urbanismo, história e arquitetura da cidade" do Departamento de Arquitetura e Urbanismo da UFSC. Chefe do Escritório Técnico de São Francisco do Sul - 111a Superintendência Regional - SC - Instituto do Patrimônio Histórico e Artístico Nacional. 